ORIGINAL ARTICLE

\title{
Integrating qualitative methods into occupational health research: a study of women flight attendants
}

\author{
T J Ballard, L Corradi, L Lauria, C Mazzanti, G Scaravelli, F Sgorbissa, P Romito, A Verdecchia
}

Occup Environ Med 2004;61:163-166. doi: 10.1136/oem.2002.006221

See end of article for authors' affiliations

\section{Correspondence to:} Dr L Lauria, Italian Institute of Health, Viale Regina Elena, 299, Rome 00161, Italy; lauria@iss.it

Accepted 1 March 2003

\begin{abstract}
Aims: To identify possible work related sources of psychosocial stress in order to develop pertinent questionnaire items for a cross-sectional health survey of 3000 Italian women flight attendants, and to solicit suggestions on improving survey participation.

Methods: Qualitative study in which 26 current and former women flight attendants participated: three focus groups of 6-7 participants each and six in-depth individual interviews. The session themes included positive and negative aspects of the job; relationships with colleagues, superiors, and passengers; perception of occupational risk for serious diseases; compatibility of work and family; and experiences of work related sources of stress and their effect on health. A transcript based analysis of the focus groups and interviews was used to identify emerging themes related to risk factors for mental health problems. Results: The participants indicated that mental health was a major concern. Several work related risk factors possibly related to adverse outcomes, such as depression and anxiety, were highlighted. These included isolation and solitude, fears of being inadequate partners and mothers due to job demands, passenger relationships, and lack of protection by employers with respect to workplace exposures and violent passengers. The information gained was used to develop a mental health module for inclusion in the health survey questionnaire which included questions on history of severe depression or anxiety, suicidal ideation or attempt, substance abuse, workplace sexual harassment, social support, leisure time activities, relationship with a partner, and role as mother.

Conclusions: Employing qualitative methods to identify work related sources of psychosocial stress enabled development of pertinent questionnaire items for a cross-sectional epidemiological study of women flight attendants. Follow up qualitative research may be necessary in order to put the cross-sectional study findings into context and to explore actions or strategies for preventing work related health problems evidenced from the survey.
\end{abstract}

$\mathrm{n}$ the past decade, several studies of women flight attendants have shown increased risks for incidence of breast cancer and malignant melanoma, possibly related to occupational exposures to cosmic radiation. ${ }^{1-4}$ A small increased risk of spontaneous abortions was found in a Finnish flight attendant study. ${ }^{5}$ As follow up to a retrospective mortality cohort study of Italian flight personnel, we designed a cross-sectional health survey of 3000 women flight attendants to study cancer incidence and reproductive health problems in relation to flight history. Because the mortality study showed an unexpected increase in suicide (6 observed deaths versus 1.8 expected, for an SMR of 3.4), ${ }^{6}$ we felt it important to incorporate a section on psychosocial risk factors and associated health outcomes into the survey questionnaire that already contained questions on work history, perception of health, reproductive health, and history of serious diseases, including cancer.

A search of the medical and psychological literature for mental health, depression, or suicide among flight attendants was negative apart from two earlier surveys that explored job strain and fatigue. ${ }^{78}$ To better understand the possible work related risk factors for mental health problems, we used qualitative methods as the most informative way to learn about dynamics of the job. The main objective of the qualitative study was to identify possible work related sources of psychosocial stress and their health effects, in order to design pertinent questions for inclusion in the crosssectional study questionnaire. An additional objective was to solicit suggestions for improving response to a postal questionnaire.

\section{METHODS}

We compiled a research team of four epidemiologists (TJB, LL, GS, AV), a sociologist (LC), two psychologists (FS, PR), and a former flight attendant (CM) to design and carry out the qualitative study. We formulated themes for the semistructured format of the focus groups and individual interviews that included the following focal points: positive and negative aspects of the work as flight attendant; relationships with superiors, colleagues, and passengers; health in general and perception of risk for health problems related to work (in particular reproductive problems and tumours); compatibility of work with family and social relationships; occupationally related stress due to work organisation, dangerous work and sexual harassment; adverse effects of stress on health, such as substance abuse, depression, anxiety and panic attacks; and solicitation of suggestions to improve the response rate of the postal questionnaire based health survey (focus groups only).

Three focus groups were conducted to provide perceptions and opinions of the group members on the selected themes, following the steps outlined in Krueger. ${ }^{9}$ Convenience sampling was employed to select participants for the first two groups-colleagues or acquaintances of the former flight attendant researcher were invited to attend, who in turn invited others until a sufficient number of women was reached for each group (similar to snowball sampling). For the third group, we contacted younger women chosen randomly from flight attendants enumerated in the original flight personnel cohor ${ }^{6}{ }^{6}$ who were less than 35 years of age in 2001. A fourth group was to be held only if new information 


\section{Main messages}

- Qualitative research methods are particularly pertinent to occupational epidemiology when little is known about certain aspects of the job that may influence the health and wellbeing of workers.

- Information obtained from this qualitative study to identify work related risk factors for adverse mental health outcomes provided useful input towards the development of a more comprehensive questionnaire for a cross-sectional epidemiological study of women flight attendants.

- Follow up qualitative research may be necessary in order to put the cross-sectional study findings into context and to explore actions or strategies for preventing work related health problems evidenced from the survey.

was obtained from the third group with respect to the first two. All potential focus group participants were sent a letter of invitation and contacted by telephone, if the telephone number was available, to arrange a meeting time. The groups were moderated by one of the authors (LC). The sessions were scheduled for two hours and were audiotaped.

In addition, six in-depth semi-structured individual interviews ${ }^{10}$ were conducted by one of the authors (FS) in the northeastern Italian city of Trieste. Letters explaining the study were distributed to the mailboxes of all flight attendants from two Italian airline companies with hubs in Trieste, and interested women were invited to contact the researcher. Each interview lasted approximately two hours and was audiotaped.

The moderators of the focus groups and interviews decided on the sequence of questions and the format to be used during their sessions. In the focus groups, potentially sensitive subjects, such as experiences with sexual harassment and individual reactions to potential emergencies on board, were covered through the use of anonymous written replies. A transcript based analysis was conducted following the techniques suggested by Krueger. ${ }^{9}$ The transcriptions and the moderators' written reports of findings and interpretation were used by the epidemiologist team to identify the frequency across focus groups and interviews with which certain concepts were discussed, the context in which the comments were made, and the specificity of the responsesgiving more weight to those based on first hand experience.

As there was no institutional bioethics committee at the time of the study, a protocol describing the methods of data collection, use of the data, and guarantees for the privacy of participants was developed and approved by two senior researchers of the Italian National Institute of Health. Oral permission to participate and to be taped was obtained from each woman at the beginning of the focus group or interview. Only first names were used during the sessions and no names were cited in written transcripts.

\section{RESULTS}

Three focus groups of 6-7 participants each were held at the Italian National Institute of Health in Rome, several weeks apart, between November 2000 and January 2001; six individual in-depth interviews were conducted in Trieste during the same time period, for a total of 26 participants. For the focus groups, 35 women were contacted by telephone; only one was not interested in participating, and 14 were unable to participate due to schedule conflicts. The median length of service as flight attendant was 26 years (range 1630 ) for the first two groups, and 11 years (range 6-22) for the third. Half of each group was comprised of women no longer in service. A fourth focus group was not indicated because little new information emerged from the third group. The six flight attendants who participated in the in-depth interviews had a median length of service of eight years (range 3-14) and all were in service. As findings from the individual interviews confirmed those from the focus groups, data from both sources were combined in order to identify emerging major themes pertaining to mental health that would lead to the inclusion of appropriate questionnaire items in the survey tool.

The job of flight attendant was described by participants as having two primary functions-safety on board and passenger service. All respondents said they chose this work in part because of the independence it offered-absence of rigid hours, opportunities to travel and to meet a variety of people. For many, these advantages still outweighed the disadvantages of the work (heavy physical labour, sleep loss, constant fatigue, and lack of control over the work schedule). However, the older women or those with children found that over time, the benefits of travel and variable schedule exacted a price in terms of stability of family and social relationships, general wellbeing, and good health. Participants concurred on the typical work related illnesses that they or their colleagues experienced: frequent colds and other respiratory problems, urinary tract infections, travel diarrhoea, indigestion, gastritis or ulcers, circulatory problems in the lower extremities, back pain, thyroiditis, deafness, and memory loss. Most but not all thought flight personnel were at increased risk for occupationally induced cancers. None had personally experienced reproductive difficulties, although many knew colleagues who had.

Depression, anxiety, and panic attacks were mentioned as having been experienced either directly in some cases or by female colleagues. In all three focus groups, the series of suicides occurring in the early 1990s among women flight attendants of one of the major Italian airlines were spontaneously brought up. Many talked about the stress of always having to adapt to home life after returning from a long tour of duty, or of feeling "cut in half" between the public self and the private self, in particular when they had children. The older women spoke of failed marriages, difficulties in working and maintaining a family, and not being assisted by their husbands in child care or other important domestic functions. The younger women, however, had fewer experiences of this type-they said they knew from the beginning what the job would involve and specifically chose the right partners to avoid the type of problems their older colleagues experienced. Nevertheless, all of the mothers talked about their sense of guilt for not being present for their children, especially at important times such as birthdays and school events. Several said that talking with colleagues helped them to overcome difficult moments and to realise that their reactions and feelings were normal in context of the work they do. There was no consensus whether flight attendants resort more often to illicit drugs or excessive alcohol use compared with other people.

There was agreement that relationships with colleagues and superiors were generally good, gender tension in the workplace was absent, and that women had as many career opportunities as their male colleagues. Sexual harassment, and in some cases physical assault on the part of superiors, had been experienced by many of the older participants, mostly at a young age or during training. Although many of the women have been subject to "advances" on the part of passengers, there was no indication that these episodes were particularly bothersome. The participants spoke of being on 
the frontline for dealing with angry or frustrated passengers due to inconveniences such as delays, thus adding to the job stress. One woman said that even normally civil people allow themselves to behave badly on board because they know they can get away with it - an attitude encouraged, some felt, by the airline companies in order to increase business. Violent or particularly aggressive passengers were felt to be increasingly common. While there is no specific law in Italy that carries criminal charges for unruly passengers, as was recently passed in Great Britain, ${ }^{11}$ it was mentioned in one focus group that companies now take precautions in certain circumstances, for example, on particular flight paths or during special events such as international soccer matches.

The women talked about their response to emergencies in the air, indicating that although they might experience palpitations or other signs of stress, their training enabled them to function safely and effectively. Several mentioned that after the birth of their children, they experienced fear of flying, a sensation unknown to them before.

Much discussion was dedicated in all focus groups and interviews to the theme of mental health, stress, and balancing work and life outside of work. Table 1 provides several exemplary quotes from participants pertaining to dealing with difficult passengers, family and social relations, isolation and solitude, feelings of being inadequate partners and mothers because of job demands, and stress related health effects.

Many participants talked about the perceived lack of institutional concern for their health and wellbeing, in particular not being adequately protected from violent passengers or workplace exposures. Most expressed general scepticism about health research on flight personnel, as "we have been studied numerous times but have never heard any results, and nothing has changed as a consequence". However, they were receptive to the idea that an independent research institution was conducting this study and that the airline companies were not involved.

Using the information gained from this exploratory qualitative study, we added a mental health module that included questions on history of serious depression or anxiety, suicidal ideation, substance abuse, workplace sexual harassment, social support, leisure-time activities, partner relationships, adequacy of their role as mothers, and division of childcare.
The focus group participants also gave many useful suggestions for improving the credibility of the questionnaire study and for increasing the response rate, such as promoting the study actively at the Rome airport and assuring potential participants of the independence of the research and respect for privacy. All participants thought that the questionnaire should be totally anonymous without a linkable identification code to personal data, and that a report of the findings should be sent to respondents who indicated an interest by mailing back a form (separately from the questionnaire) with name and address.

\section{DISCUSSION}

Stress and mental health problems were of concern to this category of working women and several work related risk factors were identified, such as isolation and solitude, fears of being inadequate partners and mothers due to job demands, difficult passenger relationships, and lack of protection on the part of employers. Isolation and solitude associated with work were described as due, in part, to being unable to maintain regular social relationships at home, but also on the job. The composition of the crew changes with each flight, resulting in constantly working with new colleagues, which was seen largely as a benefit, but might limit opportunities to develop a steady group of workplace friends for mutual support. Many participants thought that the isolation associated with the job may have contributed to the suicides among colleagues a decade before. Another source of adverse effects on health and wellbeing may come from the conflict between women's work and family roles. Difficulties in balancing work and family were described as due primarily to the frequent absences from home and little control over work schedules. Studies conducted in three Western countries showed that heavy workloads may adversely affect women's health under certain conditions, such as having small children, and may contribute to marital instability where the share of household work is perceived as being unequal. ${ }^{12}$ Passenger-flight attendant relationships may contribute to developing unnatural ways of dealing with feelings. Because flight attendants represent the airline company, they must create a friendly atmosphere and treat passengers with respect and kindness. However, this is not always reciprocal. Spontaneous reactions of anger or frustration on the part of flight attendants after being treated badly by passengers were

Table 1 Flight attendants talk about work, stress, and effects on health; quotes from focus groups and in-depth individual interviews

A. Passenger relationships

- "When dealing with irate or offensive passengers, you can't show anger because the customers are always right since they pay. Therefore it is better to avoid any confrontation".

- "In order not to react, I might walk up and down the aisle, go into the bathroom and comb my hair, and then when I am calmed down, go back to talk to the person. Staying calm is extremely important to $\mathrm{me}^{\prime \prime}$.

- "You know what they say about flight attendants - super made-up, super smiley, and super nice. Some days it's hard to stay civil. It is wearing".

- "If someone puts a hand on your bottom, you should say 'Excuse me sir, but my bottom accidentally fell into your hand".

B. Compatibility of work and family

- "You can't do this job and have children, it is too punishing".

- "With the persons you were closest to, the difficulty was to resolve situations as they occurred because you were either going or coming, always having to postpone the problems or even the joys".

C. Work related sources of stress and effects on health

- "You are away 4-5 nights, every night in a different hotel. You don't have a point of reference".

- "Never being in town when your friends go out contributes to the solitude".

- "There was an epidemic of suicides because of the solitude, for not having anyone to talk to. We are an occupation at risk".

- "The stress accumulates while I am working and I need to let it off. Unfortunately I do so with the people closest to me-I get overwhelmed and can't handle things because I am so tired; or else my colitis acts up. In one way or the other the stress comes out".

- "I think the hardest thing I have had to face is constantly having to adapt".

- "This job puts your mental stability to the test". 
not felt to be acceptable forms of corporate behaviour, as illustrated by the statements listed in part A of table 1 . In a large case study of American flight attendants in the early 1980s, Hochschild ${ }^{13}$ found that airline companies devote much time training flight attendants to handle emotions such as anger that arise in-flight as a consequence of unpleasant encounters with passengers, and that this training is given more to protect the interests of the company and to keep customers happy than to protect workers in unpleasant situations. Flight attendants are taught to pretend to feel what they do not-to act in a way that does not betray the anger one might naturally feel when being abused or insulted. Hochschild considers this dissonance of feelings, this estrangement between "self and feeling" and "self and display", to be a source of stress related to work as flight attendant, but feels that most persons in this situation learn to separate themselves from their company role and are clearly able to define for themselves when they are acting and when they are not. ${ }^{13}$ However, serious mental health disturbances may be a consequence if this delineation of the work-self and the real-self becomes difficult to maintain.

Qualitative research methodology has been advocated for use in the context of epidemiological research, ${ }^{14}$ and also in the field of occupational health intervention research. ${ }^{15}{ }^{16}$ It is particularly pertinent to occupational epidemiology when little is known about certain aspects of the job that may influence health and wellbeing of workers. Focus groups and other qualitative approaches can be used successfully in combination with quantitative studies in several ways: before initiating quantitative data collection to gain insights into the problem under study; during quantitative data collection to use triangulation to confirm findings; and as a follow up to quantitative research to suggest action strategies for problems highlighted from the questionnaire data. ${ }^{9}$

\section{Conclusions}

This qualitative study was indispensable for understanding work related factors that might affect psychosocial wellbeing of women flight attendants. By listening to the women directly, we were better able to formulate questionnaire items for the investigation of associations between work related psychosocial stress factors and mental health outcomes to include in a cross-sectional epidemiological study of 3000 women flight attendants.

It has been noted that qualitative research in occupational health takes into account the work processes and leads to prevention strategies that attempt to "adapt the work to the worker rather than the worker to work" ${ }^{14}$ For the study of
Italian women flight attendants, the initial qualitative methods lead to the development of a better tool for a quantitative study. However, we may also need to consider follow up qualitative research in order to put the crosssectional study findings into context and to explore actions or strategies for preventing work related health problems evidenced from the survey.

\section{ACKNOWLEDGEMENTS}

This study was supported by a grant from the Italian Ministry of Health.

\section{Authors' affiliations}

T J Ballard, L Lauria, C Mazzanti, G Scaravelli, A Verdecchia, Italian

National Institute of Health, Rome, Italy

L Corradi, University of Calabria, Italy

F Sgorbissa, P Romito, University of Trieste, Italy

\section{REFERENCES}

1 Pukkala E, Auvinen A, Wahlberg G. Incidence of cancer among Finnish airline cabin attendants, 1967-92. BMJ 1995;311:649-52.

2 Lynge E. Commentary: cancer in the air. Int J Epidemiol 2001;30:830-2.

3 Rafnsson V, Tulinius H, Jonasson JG, et al. Risk of breast cancer in female flight attendants: a population-based study (Iceland). Cancer Causes Control 2001;12:95-101.

4 Reynolds P, Cone J, Layefsky M, et al. Cancer incidence in California flight attendants (United States). Cancer Causes Control 2002;13:317-24.

5 Aspholm R, Lindbohm ML, Paakkulainen H, et al. Spontaneous abortions among Finnish flight attendants. J Occup Environ Med 1999:41:486-91.

6 Ballard TJ, Lagorio S, De Santis M, et al. A retrospective cohort mortality study of Italian cockpit crew and cabin attendants: 1965-96. Int J Occup Environ Health 2002;8:87-96.

7 Suvanto S, Ilmarinen J. Stress and strain in flight attendant work. Ergonomia $1989 ; 12: 85-91$.

8 Smolensky MH, Lee E, Mott D, et al. A health profile of American flight attendants. J Human Ergol 1982;11(suppl): 103-19.

9 Krueger RA. Focus groups. A practical guide for applied research, 2nd edn. Thousand Oaks, CA, London, New Delhi: Sage Publications, 1994.

10 Kvale S. Interviews. An introduction to qualitative research interviewing. Thousand Oaks, CA: Sage Publications, 1996.

11 The Air Navigation (Fifth Amendment) Order 1999. UK Department of the Environment, Transport and the Regions. http://www.nds.coi.gov.uk/coi/ coipress.nsf/1d4410efd9700935802567350059a4fa/ a89ea326b8550210802567bd00331001?OpenDocument.

12 Gjerdingen D, McGovern P, Bekker M, et al. Women's work roles and their impact on health, well-being, and career: comparisons between the United States, Sweden, and the Netherlands. Women Health 2000;31:1-20.

13 Hochschild AR. The managed heart. Commercialization of human feeling. Berkeley and Los Angeles, CA: University of California Press, 1983.

14 Black N. Why we need qualitative research. J Epidemiol Community Health 1994;48:425-6.

15 Needleman C, Needleman ML. Qualitative methods for intervention research. Am J Ind Med 1996;29:329-37.

16 Mergler D. Combining quantitative and qualitative approaches in occupational health for a better understanding of the impact of work-related disorders. Scand J Work Environ Health 1999;25(suppl 4):54-60. 